\title{
The association between dietary sodium intake and the risk of cataract: data from Korean National Health and Nutrition Examination Survey 2012
}

\author{
Jeong-Hwa Choi ${ }^{1}$ and Young-Ran $\mathrm{Heo}^{2 \dagger}$ \\ ${ }^{1}$ Department of Food Science and Nutrition, Keimyung University, Daegu 42601, Korea \\ ${ }^{2}$ Division of Food and Nutrition, Research Institute for Human Ecology, Chonnam National University, Gwangju 61186, Korea
}

\begin{abstract}
Purpose: Sodium intake is known to be a critical dietary factor in several diseases including cataract. Earlier studies have reported that excess intake of sodium may elevate the risk of cataract. However, little is known about this in Koreans. Thus, the purpose of this study was to examine whether dietary intake of sodium and potassium might modify the risk of cataract. Methods: A total of 1,319 males (219 cases) and 1,966 females (369 cases) from Korean National Health and Nutrition Examination Survey 2012 were analyzed. Energy adjusted dietary intakes of sodium and potassium and their ratios were evaluated to ascertain their associations with the risk of cataract. Dietary intake levels were stratified into quartiles and their risk modifying effects were estimated with logistic regression models with or without subjects' socio-economic characteristics and life styles for each sex. Results: Findings suggested that various descriptive factors were associated with the risk of cataract either in males or females. Males' intake levels of sodium and potassium and their ratios did not differ between phenotypes. Higher intakes or higher ratio was not associated with the risk of cataract. In contrast, female controls had higher intakes of sodium and potassium. Higher intake of potassium reduced the risk of cataract in females. However, such association was not retained when subjects' socioeconomic status and life styles were factored into the analysis. Conclusion: Dietary sodium and potassium intakes minimally affected the risk of cataract in Korean males and females. More studies are needed to ascertain the true pathological effect of sodium intake on cataract aetiology.
\end{abstract}

KEY WORDS: sodium, potassium, sodium/potassium ratio, cataract

\section{Introduction}

Excess intake of sodium is thought to be a major dietary factor in human health and diseases. Previous studies have reported that high sodium intake is associated with various disorders, including hypertension [1], cardiovascular disease [2], cancer [3], innate immunity [4] and obesity [4], For instance, high intake of sodium is associated with stiffening and perturbation of arteries impediment and nitric oxide-releasing process [5,6]. Dietary sodium intake is also correlated with adiposity and changes of immune responserelated markers including adiponectin, tumour necrosis factor- $\alpha$, and insulin resistance [7,8]. Furthermore, recent findings have suggested that excess dietary sodium might be associated with optical disorders, including cataract with increased risk of 2.4 folds [9].

Cataract is a type of optical disease with clouding of normal lens of eyes. Cataract is a leading cause of loss of eye sight. It often develops in people aged over 40s, and, therefore becoming a critical health problem in aging population [10]. Approximately 905,975 Koreans were diagnosed with cataract in 2014 [11]. Several factors are known to be associated with the development and progression of cataract, including age, sex, excessive exposure to ultra violet light, tobacco smoking, alcohol drinking, and diabetes milieus [12,13]. Additionally, high consumption of meat also increase the risk of cataract while greater intake of vegetables, fruits, and whole grains can reduce the prevalence of cataract $[14,15]$. Such protective effect of dietary consumption of fruits, vegetables, and whole grains on cataract has been shown to be associated with their high contents of antioxidants and other phytochemical compounds [16]. Multiple exterior/interior stimuli can lead to stresses and oxidation

Received: April 8, 2019/Revised: May 28, 2019 / Accepted: May 30, 2019

${ }^{\dagger}$ To whom correspondence should be addressed.

tel: +82-62-530-1338, e-mail: yrhuh@jnu.ac.kr

This is an Open Access article distributed under the terms of the Creative Commons Attribution Non-Commercial License (http://creativecommons. org/licenses/by-nc/3.0/) which permits unrestricted non-commercial use, distribution, and reproduction in any medium, provided the original work is properly cited. 
of lipid and protein $[13,16]$, resulting in abnormality and accumulation of cellular proteins and the development of cataract $[13,16]$. Therefore, high intake of antioxidant is possibly effective in reducing the risk of cataract [14]. Our recent study has shown that abundant intake of fruits and vegetables is protective against cataract in Korean males [17]. Furthermore, different types of fruits and vegetables (such as total vegetables, fruits, salted vegetables, and non-salted vegetables) possess differential modifying effect on the risk of cataract [17]. This suggests that, although antioxidants and phytochemicals that are rich in these foods could be major modifiers in reducing the risk of cataract, other nutritional intake such as sodium and potassium could be associated with the risk of cataract. One Korean study has reported that 24-hour urine sodium excretion level is associated with the risk of cataract [18]. However, the effect of dietary sodium intake estimated from dietary record on the risk of cataract has not been clearly verified yet. More evidences are required to verify the effect of dietary sodium intake on the development of cataract in a Korean population.

Therefore, the objective of this study was to determine the association of dietary sodium intake and the risk of cataract in a Korean population using data from Korean National Health and Nutrition Examination Survey (KNHANES) 2012. Effects of dietary potassium intake and the ratio of sodium intake to potassium intake on the risk of cataract were also determined.

\section{Methods}

\section{Study subject selection}

This study was performed using data from KNHANES 2012. Ethical approval of KNHANES was obtained from Korean CDC (2012-01EXP-01-2C). Study protocols were additionally reviewed by Institutional Committee (1040198160921-HR-087-01). Among a total of 8,058 subjects, 3,556 who were less than 40 years old were excluded. Individuals who had missing descriptive data, those who had no cataract diagnosis results, no information for food or nutrient intake, and those whose energy intake was less than 500 or more than $5,000 \mathrm{kcal}$ were also excluded. Subjects with excess intake of vitamin A (>3,000 ug RAE) were additionally excluded. Finally, a total of 3,285

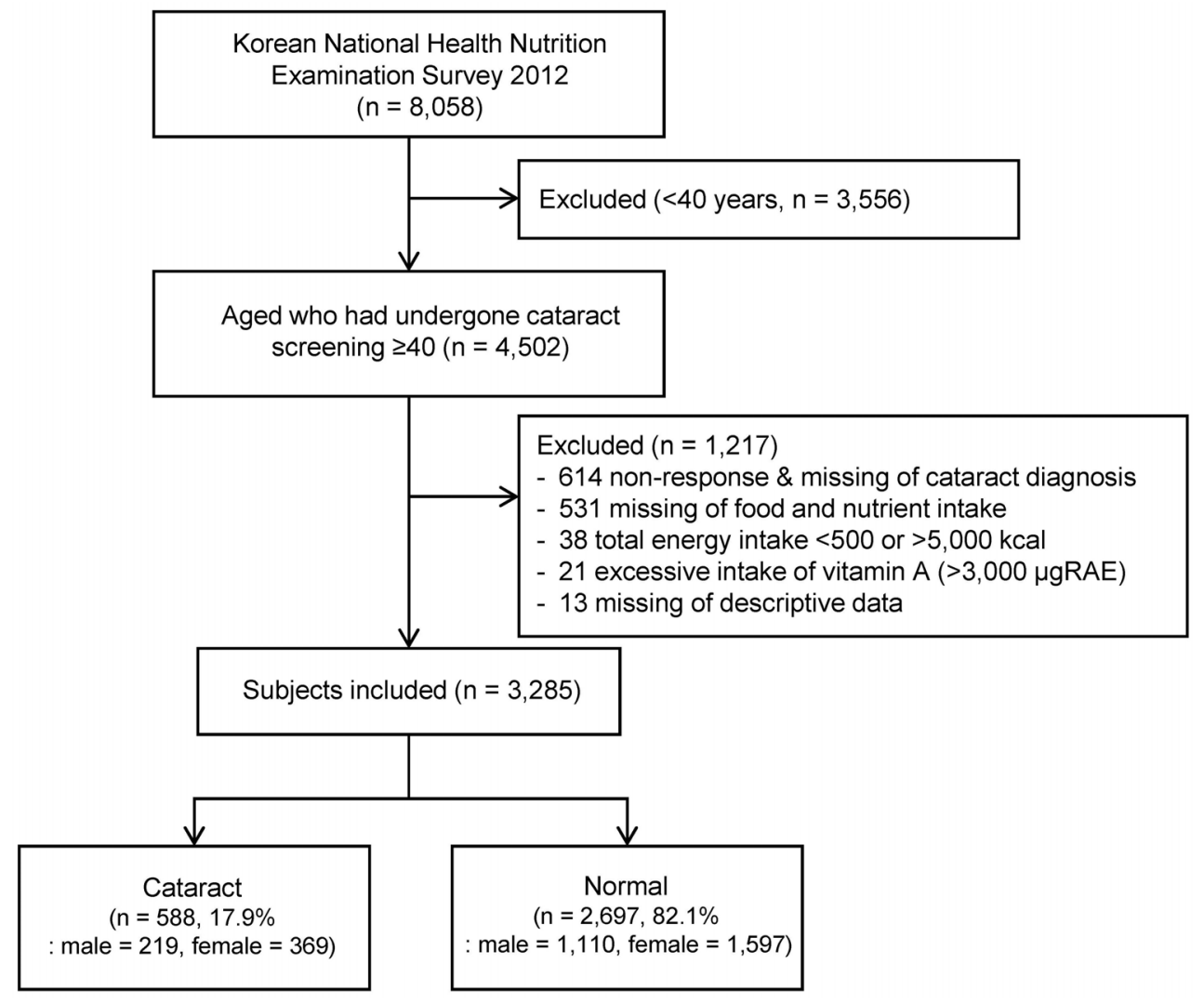

Fig. 1. A simplified flow chart showing the selection of study subjects 
Koreans (588 cases and 2,697 controls) were analyzed to determine the association of the incidence of cataract with sodium and potassium intakes. Fig. 1 shows the procedure used for subject selection.

\section{Data collection and analysis}

Data of 3,285 subjects' sex, age, household income, practice of regular exercise, education, tobacco smoking, alcohol drinking, and the presence of diabetes mellitus were extracted from KNHANES 2012. Details for classification and analyses were described previously [17]. Dietary intake was obtained and adjusted with total energy intake prior to analysis using Willet's residual method [19].

\section{Statistical analysis}

Student's t-test and chi-squared test were used to compare general characteristics of study population according to the type of variables. To compare the level of nutritional intake between cases and controls, Student's t-test was used. Associations of the risk of cataract with sodium intake, potassium intake, and their ratio were computed with logistic regression assessments. Results are presented with the odds ratios (ORs) and 95\% confidence intervals ( $95 \%$ CIs). Models were established with or without adjustments for age, education, household income, physical activity, smoking, alcohol drinking, and the presence of diabetes mellitus. All statistical analyses were performed with SAS 9.3 (SAS Institute Inc., Cary, NC, USA) and two-sided p-value of less than 0.05 was considered significant.

\section{Results}

\section{General characteristics of study subjects}

To understand study subjects' socio-economic and health related background, sex, age, household income, practice of regular exercise, education, tobacco smoking, alcohol drinking, and the presence of diabetes mellitus were analysed in males and females, respectively (Table 1). Statistical results revealed that both male and female cataract cases were older than controls $(p<0.0001)$. Their levels of education, household incomes, and the presence of diabetes mellitus were also different from those of controls. However, BMIs of cases did not differ from those of controls for males or females. Lastly, smoking status of cases differed from that of controls in males $(p=0.0002)$, but not in females. These results suggest that the risk of cataract could be modified by individual's socioeconomic and life styles. For this reason, those factors were considered in the statistical models later.

Nutritional intake levels in each cataract phenotype

Table 2 presented sodium intake level, potassium intake level, and their ratio for cases and controls by sex. In males, there was no significant difference in dietary sodium intake, potassium intake, their ratio, or vitamin A intake level between cases and controls. However, controls had more energy intake than cases in males $(2,227.4 \pm 772.4$ and $1,936.5 \pm 630.5 \mathrm{kcal} / \mathrm{day}, \mathrm{p}<0.0001)$. By contrast, in females, controls had more sodium intake $(4,482.0 \pm$ 2,529.0 and 4,251.2 $\pm 2,642.7 \mathrm{mg} /$ day, $\mathrm{p}=0.0118$ ), potassium intake $(3,086.4 \pm 1,201.3$ and $2,917.0 \pm 1,621.5 \mathrm{mg} /$ day, $\mathrm{p}<0.0001)$, total energy intake $(1,654.6 \pm 590.4$ and $1,508.5 \pm 536.3 \mathrm{kcal} / \mathrm{day}, \mathrm{p}<0.0001)$ and vitamin A intake $(808.7 \pm 567.1$ versus $646.9 \pm 531.9 \mu \mathrm{gRAE}, \mathrm{p}<0.0001)$ than cases. On the other hand, the ratio of sodium intake to potassium intake for controls did not differ from that for cases.

Subjects' sodium intake, potassium intake, and their ratio were stratified into quartiles. Fig. 2 presents the level of dietary intake for each quartile group in males and females. Mean sodium intakes for male controls and cases were $2,302.9 \pm 502.48$ and $2,257.29 \pm 613.28 \mathrm{mg}$ /day, respectively. Mean potassium intake levels were $1,844.7$ \pm 266.22 and $1,721.54 \pm 317.0 \mathrm{mg} /$ day in each phenotype, respectively. Mean nutritional intake was increased with quartiles. The fourth quartile of sodium and potassium intake levels were approximately 4 and 2.3 times of the 1st quartile, respectively, in both cases and controls. Ratios of sodium intake to potassium intake in controls and cases were 0.85 and 0.88 , respectively. They were increased to 2.76 and 2.87 (approximately 3 folds), respectively, for the 4th quartile. Although levels of intake in females were lower than those in males, the trend towards consumption for sodium and potassium in females were similar to that in males. Female cases and controls in the 1st quartile had sodium intakes of 2,090.8 \pm 500.7 and $1,960.4 \pm 572.7 \mathrm{mg} /$ day, respectively. Their levels of potassium intake were $1,901.61 \pm 329.2$ and $1,812.6 \pm$ $323.1 \mathrm{mg} /$ day, respectively. Such levels resulted in ratios of intake of 0.72 and 0.7 , respectively. In males, intakes 
Table 1. General characteristics of study subjects taking sex and cataract phenotype into account

\begin{tabular}{|c|c|c|c|c|c|c|c|c|}
\hline & \multicolumn{3}{|c|}{ Males } & \multicolumn{5}{|c|}{ Females } \\
\hline & $\begin{array}{c}\text { All } \\
(\mathrm{n}=1,319,100 \%)\end{array}$ & $\begin{array}{c}\text { Control } \\
(\mathrm{n}=1,100,83.4 \%)\end{array}$ & $\begin{array}{c}\text { Cataract } \\
(n=219,16.6 \%)\end{array}$ & $p^{1)}$ & $\begin{array}{c}\text { All } \\
(n=1,966,100 \%)\end{array}$ & $\begin{array}{c}\text { Control } \\
(n=1,597,81.2 \%)\end{array}$ & $\begin{array}{c}\text { Cataract } \\
(n=369,18.8 \%)\end{array}$ & $p$ \\
\hline$\overline{\text { Age }(\text { year } \pm S D)^{2)}}$ & $60.8 \pm 11.5$ & $58.9 \pm 11.1$ & $70.5 \pm 8.2$ & $<0.0001^{3)}$ & $59.7 \pm 11.8$ & $57 \pm 10.9$ & $71.4 \pm 7.8$ & $<0.0001$ \\
\hline $\mathrm{BMl}\left(\mathrm{kg} / \mathrm{m}^{2} \pm \mathrm{SD}\right)$ & $23.9 \pm 2.9$ & $24 \pm 2.9$ & $23.5 \pm 2.8$ & 0.0537 & $24 \pm 3.3$ & $24 \pm 3.3$ & $24.2 \pm 3.3$ & 0.3724 \\
\hline \multicolumn{9}{|l|}{ Education ${ }^{4}$} \\
\hline$<$ Elementary & $359(27.22)$ & 287 (26.09) & $72(32.88)$ & 0.0225 & $889(45.22)$ & $614(38.45)$ & 275 (74.53) & $<0.0001$ \\
\hline Middle & $194(14.71)$ & $158(14.36)$ & $36(16.44)$ & & $258(13.12)$ & $226(14.15)$ & $32(8.67)$ & \\
\hline High & $424(32.15)$ & $353(32.09)$ & $71(32.42)$ & & $514(26.14)$ & $473(29.62)$ & $41(11.11)$ & \\
\hline > College & $342(25.93)$ & $302(27.45)$ & $40(18.26)$ & & $305(15.51)$ & $284(17.78)$ & $21(5.69)$ & \\
\hline \multicolumn{9}{|l|}{ Household income } \\
\hline Low & $290(21.99)$ & $212(19.27)$ & $78(35.62)$ & $<0.0001$ & $539(27.42)$ & $344(21.54)$ & $195(52.85)$ & $<0.0001$ \\
\hline Mid-low & $358(27.14)$ & 287 (26.09) & $71(32.42)$ & & $486(24.72)$ & $402(25.17)$ & $84(22.76)$ & \\
\hline Mid-high & $312(23.65)$ & $278(25.27)$ & $34(15.53)$ & & $437(22.23)$ & $389(24.36)$ & 48 (13.01) & \\
\hline High & $359(27.22)$ & $323(29.36)$ & $36(16.44)$ & & $504(25.64)$ & $462(28.93)$ & $42(11.38)$ & \\
\hline \multicolumn{9}{|c|}{ Regular physical activity } \\
\hline No & $1,135(86.05)$ & 939 (85.36) & $196(89.5)$ & 0.1068 & $1,779(90.49)$ & $1,422(89.04)$ & 357 (96.75) & $<0.0001$ \\
\hline Yes & $184(13.95)$ & $161(14.64)$ & $23(10.5)$ & & $187(9.51)$ & 175 (10.96) & $12(3.25)$ & \\
\hline \multicolumn{9}{|l|}{ Tobacco Smoking } \\
\hline Never & $225(17.06)$ & $183(16.64)$ & $42(19.18)$ & 0.0002 & $1,824(92.78)$ & 1,484 (92.92) & $340(92.14)$ & 0.5818 \\
\hline Past & $684(51.86)$ & 549 (49.91) & $135(61.64)$ & & $73(3.71)$ & $56(3.51)$ & $17(4.61)$ & \\
\hline Current & $410(31.08)$ & $368(33.45)$ & $42(19.18)$ & & $69(3.51)$ & $57(3.57)$ & $12(3.25)$ & \\
\hline \multicolumn{9}{|l|}{ Alcohol drinking } \\
\hline Never & $214(16.22)$ & $174(15.82)$ & $40(18.26)$ & 0.3698 & $415(21.11)$ & $326(20.41)$ & $89(24.12)$ & 0.1159 \\
\hline Ever & 1,105 (83.78) & $926(84.18)$ & $179(81.74)$ & & 1,551 (78.89) & 1,271 (79.59) & $280(75.88)$ & \\
\hline \multicolumn{9}{|l|}{ Diabetes mellitus } \\
\hline No & $1,139(86.35)$ & 979 (89) & $160(73.06)$ & $<0.0001$ & 1,764 (89.73) & 1,475 (92.36) & 289 (78.32) & $<0.0001$ \\
\hline Yes & $180(13.65)$ & $121(11)$ & 59 (26.94) & & $202(10.27)$ & $122(7.64)$ & $80(21.68)$ & \\
\hline
\end{tabular}

1) p-values from Chi-squared test except for age and BMI (body mass index)

2) Standard deviation

3) p-value from Student's t-test

4) Number of subjects (\%) 
Table 2. Intake of sodium and potassium and their ratio for males and females

\begin{tabular}{|c|c|c|c|c|}
\hline & All & Control & Cataract & $p^{1)}$ \\
\hline Males & $\mathrm{n}=1,319$ & $\mathrm{n}=1,100$ & $n=219$ & \\
\hline Sodium (mg/day) & $4,564.8 \pm 2,400.8$ & $4,599.1 \pm 2,397.9$ & $4,392.6 \pm 2,413.5$ & 0.1336 \\
\hline Potassium (mg/day) & $2,852.9 \pm 1,086.6$ & $2,867.1 \pm 1,092.4$ & $2,781.6 \pm 1,056.8$ & 0.1002 \\
\hline Sodium/potassium & $1.68 \pm 0.84$ & $1.69 \pm 0.84$ & $1.66 \pm 0.83$ & 0.7322 \\
\hline Total energy intake (kcal) & $2,179.1 \pm 758.2$ & $2,227.4 \pm 772.4$ & $1,936.5 \pm 630.5$ & $<0.0001$ \\
\hline Vitamin $A(\mu g R A E)^{2)}$ & $670.7 \pm 470.5$ & $676.1 \pm 466.4$ & $643.9 \pm 490.8$ & 0.3729 \\
\hline Females & $n=1,966$ & $\mathrm{n}=1,597$ & $n=369$ & \\
\hline Sodium (mg/day) & $4,438.6 \pm 2,551.6$ & $4,482.0 \pm 2,529.0$ & $4251.2 \pm 2642.7$ & 0.0118 \\
\hline Potassium (mg/day) & $3,054.6 \pm 1,291.8$ & $3,086.4 \pm 1,201.3$ & $2,917 \pm 1,621.5$ & $<0.0001$ \\
\hline Sodium/potassium & $1.56 \pm 0.88$ & $1.55 \pm 0.89$ & $1.57 \pm 0.86$ & 0.7148 \\
\hline Total energy intake (kcal) & $1,627.2 \pm 583.3$ & $1,654.6 \pm 590.4$ & $1,508.5 \pm 536.3$ & $<0.0001$ \\
\hline Vitamin A ( $\mu$ gRAE) & $778.3 \pm 564.1$ & $808.7 \pm 567.1$ & $646.9 \pm 531.9$ & $<0.0001$ \\
\hline
\end{tabular}

1) p-values from Student's t-tests

2) RAE: retinol activity equivalent

(A)

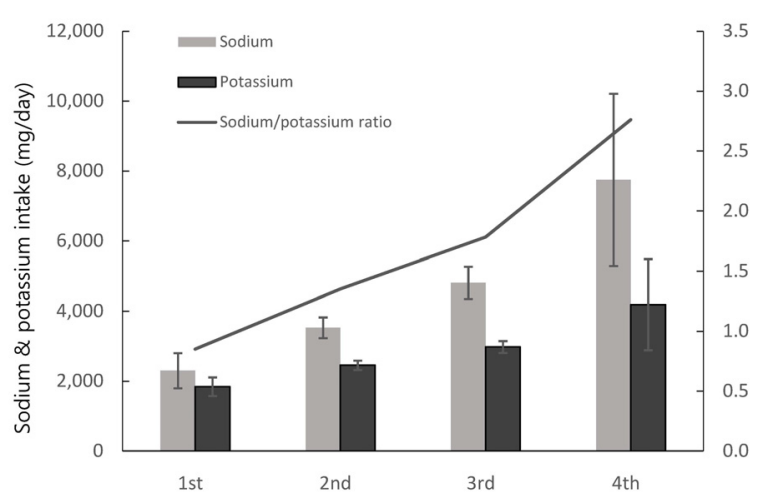

(C)

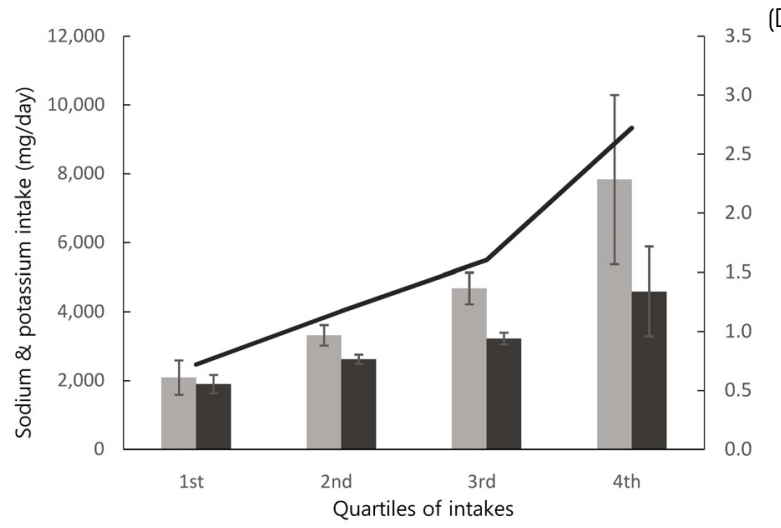

(B)

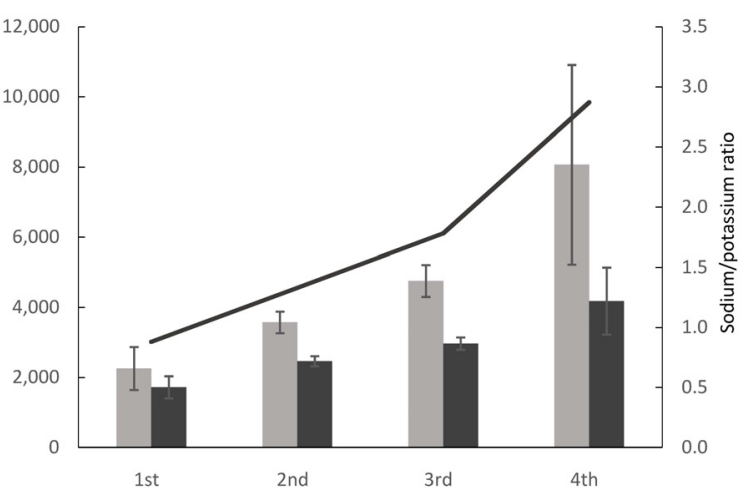

(D)

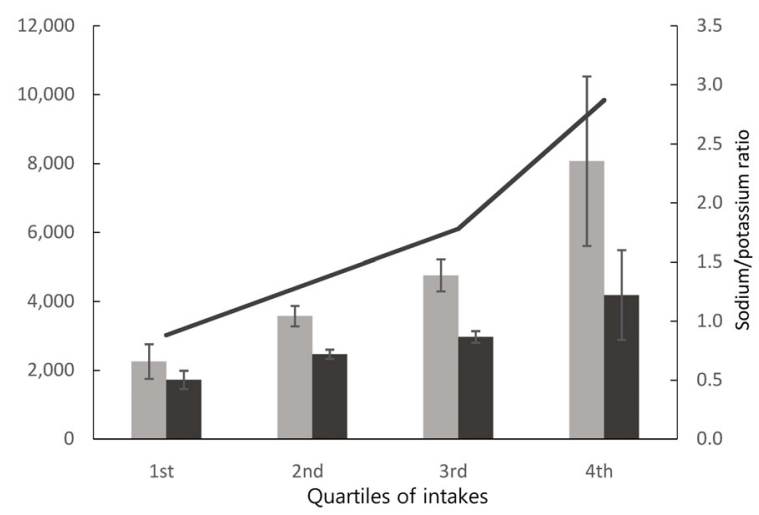

Fig. 2. Mean intake of sodium and potassium and their ratio for each quartile group in male controls (A) and cases (B) and in female controls (C) and cases (D)

of these nutrients were increased 3.7 and 4.1 times in the 4th quartile in each phenotype. The ratio of their intake did not differ in each phenotype. It was increased by approximately 3.7 times in both female cases and female controls.
Associations of the risk of cataract with dietary sodium intake and potassium intake

Associations of the risk of cataract with sodium intake, potassium intake, and their ratio were estimated by taking quartiles of intake level in account (Table 3). Logistic regression models suggested that dietary sodium, potassium 
282 / Dietary sodium and risk of cataract

Table 3. Odds ratios and $95 \%$ confidence intervals for cataract risk according to quartiles of sodium, potassium, and their ratio

\begin{tabular}{|c|c|c|c|c|c|}
\hline & $1^{\text {st }}$ quartile & $\begin{array}{l}2^{\text {nd }} \text { quartile } \\
\text { OR }(95 \% \mathrm{Cl})^{11}\end{array}$ & $\begin{array}{l}3^{\text {rd }} \text { quartile } \\
\text { OR }(95 \% \mathrm{Cl})\end{array}$ & $\begin{array}{l}4^{\text {th }} \text { quartile } \\
\text { OR }(95 \% \mathrm{Cl})\end{array}$ & $\mathrm{p}$ for trend \\
\hline \multicolumn{6}{|l|}{ Males } \\
\hline \multicolumn{6}{|c|}{ Sodium intake } \\
\hline Model $\left.\right|^{2)}$ & Reference & $0.825(0.551 \sim 1.236)$ & $0.984(0.667 \sim 1.451)$ & $0.667(0.436 \sim 1.02)$ & 0.1872 \\
\hline Model $\|^{3)}$ & Reference & $1.14(0.723 \sim 1.798)$ & $1.199(0.774 \sim 1.86)$ & $0.724(0.452 \sim 1.161)$ & 0.2824 \\
\hline \multicolumn{6}{|c|}{ Potassium intake } \\
\hline Model I & Reference & $0.984(0.665 \sim 1.455)$ & $0.661(0.431 \sim 1.015)$ & $0.887(0.595 \sim 1.323)$ & 0.1447 \\
\hline Model ॥ & Reference & $1.202(0.767 \sim 1.882)$ & $0.841(0.517 \sim 1.367)$ & $0.847(0.533 \sim 1.344)$ & 0.1287 \\
\hline \multicolumn{6}{|c|}{ Sodium/potassium } \\
\hline Model I & Reference & $0.734(0.486 \sim 1.109)$ & $0.922(0.623 \sim 1.363)$ & $0.766(0.509 \sim 1.151)$ & 0.8419 \\
\hline Model II & Reference & $0.739(0.464 \sim 1.178)$ & $1.167(0.748 \sim 1.82)$ & $0.762(0.479 \sim 1.211)$ & 0.9989 \\
\hline \multicolumn{6}{|l|}{ Females } \\
\hline \multicolumn{6}{|c|}{ Sodium intake } \\
\hline Model I & Reference & $0.833(0.611 \sim 1.135)$ & $0.768(0.56 \sim 1.052)$ & $0.73(0.531 \sim 1.003)$ & 0.0149 \\
\hline Model ॥ & Reference & $1.218(0.839 \sim 1.768)$ & $1.017(0.7 \sim 1.478)$ & $0.985(0.677 \sim 1.433)$ & 0.3931 \\
\hline \multicolumn{6}{|c|}{ Potassium intake } \\
\hline Model I & Reference & $0.634(0.468 \sim 0.861)$ & $0.604(0.444 \sim 0.823)$ & $0.514(0.372 \sim 0.709)$ & $<0.0001$ \\
\hline Model ॥ & Reference & $1.188(0.823 \sim 1.714)$ & $1.424(0.974 \sim 2.084)$ & $1.402(0.945 \sim 2.08)$ & 0.1373 \\
\hline \multicolumn{6}{|c|}{ Sodium/potassium } \\
\hline Model I & Reference & $0.945(0.686 \sim 1.301)$ & $0.874(0.631 \sim 1.21)$ & $1.063(0.778 \sim 1.453)$ & 0.3877 \\
\hline Model II & Reference & $0.921(0.63 \sim 1.345)$ & $0.75(0.509 \sim 1.107)$ & $0.75(0.517 \sim 1.089)$ & 0.2055 \\
\hline
\end{tabular}

1) OR, odds ratio; $95 \% \mathrm{Cl}, 95 \%$ confidence interval

2) Model I: unadjusted

3) Model II: adjusted for age, education, income, physical activity, smoking, alcohol drinking, and the presence of diabetes mellitus,

intake, and their ratio failed to show a decisive modifying effect on the risk of cataract in males. Such null association was not changed in additional statistical analyses after adjusting for age, education, income, physical activity, smoking, alcohol drinking, and the incidence of diabetes mellitus. In females, higher intake of potassium decreased the risk for cataract by approximately 50\% (95\% CI: 0.372 $\sim 0.709$ ) compared to the lowest intake. However, when subjects' socio-economic factors and other factors were adjusted for, increased intake of potassium elevated the risk of cataract, although such elevation was not statistically significant. Neither sodium intake nor the ratio of sodium intake to potassium intake showed any meaningful effect on the risk of cataract.

\section{Discussion}

Sodium intake has been studied as a major dietary risk factor in many disorders including cataract. In this study, effects of dietary sodium intake, potassium intake, and their ratio on cataract prevalence were evaluated. Results suggested that dietary intake of sodium was not associated with the prevalence of cataract.
Previous observational studies have provided the evidence that excessive intake of sodium has pathological effect on the onset of cataract $[9,20]$. However, the exact mechanism of action remains unknown. The imbalance of sodium and potassium level in aqueous humor and the lens might be contributed to cataract's development. High intake of sodium could lead to increased volume and expansion of fluid and lens opacities via alteration of sodium/potassium channel capacity, hence resulting in the onset of cataract [21,22]. This could explain why restriction of dietary sodium is effective in preventing cataracts in murine models in vivo [23].

In Italian and Australian human studies $[9,13]$, patients with cataract have decisively higher intakes of sodium compared to normal controls. One previous Korean study has also suggested that cataract phenotype is associated with higher intake of dietary sodium with $10 \%$ of increased risk [18]. However, this risk-modifying effect of dietary sodium was estimated using spot urinary excretion level. Although this technique may support more precise estimation of subjects' information regarding sodium intake [24], the collection of data and the experimental process are complex. They may not be appropriate for large-scaled 
epidemiological study [25]. Therefore, in this study, we estimated with the association of sodium intake with the risk of cataract using sole dietary intake from food frequency questionnaires. However, findings of this study differed from those of earlier report. Dietary intake of sodium, potassium, or their ratio was not significantly associated with the prevalence of cataract. Although higher potassium intake could protect against the development of cataract in females, such significance was nullified when subjects' other socio-economics and life style factors were adjusted for. A few hypotheses could be proposed to explain this. First, food frequency questionnaire is commonly used to collect population's dietary data. However, it has some limitations, including low accuracy and recall bias via under-reporting. In addition, difficulties in the standardization of recipe and salt use are present [26]. Furthermore, dietary data of KNHANES were estimated with a single day of 24-hours recall method which might lead to the imprecision in dietary sodium intake estimation. These may result in inconsistency of findings between studies. Second, dietary sodium intake may have influence on the onset of cataract. However, subjects' other socio-economic and life style characteristics were more dominantly or closely associated with cataract. As reported earlier, these environmental factors are known to be critical modifiers of the risk of cataract. Low household income and low educational are greatly associated with the risk of cataract with adjusted OR of 1.76 and 1.85, respectively. Moreover, age of more than 50 years old elevated the risk distinctively by approximately 15 -folds [18]. Although these socioeconomic and life style factors were adjusted for in our analysis models, their effects might not have been controlled sufficiently. Our previous findings have shown that abundant intake of vegetables and fruits can reduce the risk of development of cataract [17]. Higher or more frequent intake of these foods are closely related with socio-economic status surrounding individuals [27,28]. Furthermore, individuals with low household income and educational background may have limited access to medical service and information of health management $[29,30]$. For these reasons, the risk modifying effect of sodium and potassium on the prevalence of cataract may not be clearly observed in this study independently. Lastly, nutrients are generally consumed in combined from and highly correlated. The estimation of the effect of a single or a few nutrients may provide limited information to understand the pathoaetiology of cataract. Effects of dietary factors including antioxidant, phytochemicals, lutein, zeaxanthin, and so on reported in experimental and/or epidemiological research were not examined in this study. Their potential influences could not be dismissed. Thus, multiple approaches considering individual's socio-economic and life style status as well as dietary consumption are needed to effectively prevent cataract.

In conclusion, dietary sodium intake, potassium intake, or their ratio was not associated with the onset of cataract in a Korean population. Studies with more information and in-depth analyses are required to clarify the pathological effect of nutrient on cataract aetiology.

\section{Summary}

This study examined the association of cataract risk with dietary sodium intake and potassium intake using data from KNHANES 2012. Our findings suggested that sex, age, household income, practice of regular exercise, education, tobacco smoking, alcohol drinking, and the presence of diabetes mellitus were associated with cataract phenotype in either males and females. Dietary intake of sodium, potassium, and their ratio differed between cases and controls only in females. However, differential consumption level of sodium or potassium was not associated with the development or progression of cataract. Our findings suggest that various approaches that take individual's socio-economic and life styles as well as other dietary factors into account rather than taking single nutrient intake into account may be able to more effectively reduce the risk of cataract in Koreans.

\section{ORCID}

Jeong-Hwa Choi: https://orcid.org/0000-0003-4730-6544

Young-Ran Heo: https://orcid.org/0000-0001-5476-3714

\section{References}

1. Dobrian AD, Schriver SD, Lynch T, Prewitt RL. Effect of salt on hypertension and oxidative stress in a rat model of diet-induced obesity. Am J Physiol Renal Physiol 2003; 285(4): F619-F628.

2. Bibbins-Domingo K, Chertow GM, Coxson PG, Moran A, Lightwood JM, Pletcher MJ, et al. Projected effect of dietary salt reductions on future cardiovascular disease. N Engl J Med 
2010; 362(7): 590-599.

3. Woo HD, Park S, Oh K, Kim HJ, Shin HR, Moon HK, et al. Diet and cancer risk in the Korean population: a metaanalysis. Asian Pac J Cancer Prev 2014; 15(19): 8509-8519.

4. Calder PC, Ahluwalia N, Brouns F, Buetler T, Clement K, Cunningham $\mathrm{K}$, et al. Dietary factors and low-grade inflammation in relation to overweight and obesity. Br J Nutr 2011; 106(Suppl 3): S5-S78.

5. Büssemaker E, Hillebrand U, Hausberg M, Pavenstädt $H$, Oberleithner H. Pathogenesis of hypertension: interactions among sodium, potassium, and aldosterone. Am J Kidney Dis 2010; 55(6): 1111-1120.

6. Cook NR, Obarzanek E, Cutler JA, Buring JE, Rexrode KM, Kumanyika SK, et al. Joint effects of sodium and potassium intake on subsequent cardiovascular disease: the Trials of Hypertension Prevention follow-up study. Arch Intern Med 2009; 169(1): 32-40.

7. Rodrigues Telini LS, de Carvalho Beduschi G, Caramori JC, Castro JH, Martin LC, Barretti P. Effect of dietary sodium restriction on body water, blood pressure, and inflammation in hemodialysis patients: a prospective randomized controlled study. Int Urol Nephrol 2014; 46(1): 91-97.

8. Costa AP, de Paula RC, Carvalho GF, Araújo JP, Andrade JM, de Almeida OL, et al. High sodium intake adversely affects oxidative-inflammatory response, cardiac remodelling and mortality after myocardial infarction. Atherosclerosis 2012; 222(1): 284-291.

9. Tavani A, Negri E, La Vecchia C. Food and nutrient intake and risk of cataract. Ann Epidemiol 1996; 6(1): 41-46.

10. West SK, Valmadrid CT. Epidemiology of risk factors for age-related cataract. Surv Ophthalmol 1995; 39(4): 323-334.

11. Ministry of Health and Welfare (KR). Domestic health and welfare news. Health Welf Policy Forum 2015; (229): 94-110.

12. Chang JR, Koo E, Agrón E, Hallak J, Clemons T, Azar D, et al. Risk factors associated with incident cataracts and cataract surgery in the Age-related Eye Disease Study (AREDS): AREDS report number 32. Ophthalmology 2011; 118(11): 2113-2119.

13. McCarty CA, Mukesh BN, Fu CL, Taylor HR. The epidemiology of cataract in Australia. Am J Ophthalmol 1999; 128(4): 446-465.

14. Theodoropoulou S, Samoli E, Theodossiadis PG, Papathanassiou M, Lagiou A, Lagiou P, et al. Diet and cataract: a case-control study. Int Ophthalmol 2014; 34(1): 59-68.

15. Rautiainen S, Lindblad BE, Morgenstern R, Wolk A. Total antioxidant capacity of the diet and risk of age-related cataract: a population-based prospective cohort of women. JAMA Ophthalmol 2014; 132(3): 247-252.

16. Beebe DC. Nuclear cataracts and nutrition: hope for intervention early and late in life. Invest Ophthalmol Vis Sci 1998; 39(9):
1531-1534.

17. Lee E, Choi JH, Heo YR. Intake of fruits and vegetables may modify the risk of cataract in Korean males: data from Korean National Health and Nutrition Examination Survey 2012. J Nutr Health 2018; 51(5): 423-432.

18. Bae JH, Shin DS, Lee SC, Hwang IC. Sodium intake and socioeconomic status as risk factors for development of age-related cataracts: the Korea National Health and Nutrition Examination Survey. PLoS One 2015; 10(8): e0136218.

19. Willett WC, Howe GR, Kushi LH. Adjustment for total energy intake in epidemiologic studies. Am J Clin Nutr 1997; 65(4 Suppl): 1220S-1228S.

20. Cumming RG, Mitchell P, Smith W. Dietary sodium intake and cataract: the Blue Mountains Eye Study. Am J Epidemiol 2000; 151(6): 624-626.

21. Rodríguez-Sargent C, Cangiano JL, Berríos Cabán G, Marrero E, Martínez-Maldonado M. Cataracts and hypertension in salt-sensitive rats. A possible ion transport defect. Hypertension 1987; 9(3): 304-308.

22. Mirsamadi M, Nourmohammadi I, Imamian M. Comparative study of serum $\mathrm{Na}(+)$ and $\mathrm{K}(+)$ levels in senile cataract patients and normal individuals. Int J Med Sci 2004; 1(3): 165-169.

23. Rodríguez-Sargent C, Berrios G, Irrizarry JE, Estapé ES, Cangiano JL, Martínez-Maldonado M. Prevention and reversal of cataracts in genetically hypertensive rats through sodium restriction. Invest Ophthalmol Vis Sci 1989.30(11): 2356-2360.

24. Mann SJ, Gerber LM. Estimation of 24-hour sodium excretion from spot urine samples. J Clin Hypertens (Greenwich) 2010; 12(3): 174-180

25. Cho YG. Sodium intake estimated from spot urine samples and the prevalence of metabolic syndrome in the Korea National Health and Nutrition Examination Survey. Korean J Fam Med 2017; 38(4): 171-172.

26. Shim JS, Oh K, Kim HC. Dietary assessment methods in epidemiologic studies. Epidemiol Health. 2014; 36: e2014009.

27. Miller V, Yusuf S, Chow CK, Dehghan M, Corsi DJ, Lock $\mathrm{K}$, et al. Availability, affordability, and consumption of fruits and vegetables in 18 countries across income levels: findings from the Prospective Urban Rural Epidemiology (PURE) study. Lancet Glob Health 2016; 4(10): e695-e703.

28. Hur I, Jang MJ, Oh K. Food and nutrient intakes according to income in Korean men and women. Osong Public Health Res Perspect 2011; 2(3): 192-197.

29. Dandona R, Dandona L. Socioeconomic status and blindness. Br J Ophthalmol 2001; 85(12): 1484-1488.

30. Wu R, Wang JJ, Mitchell P, Lamoureux EL, Zheng Y, Rochtchina E, et al. Smoking, socioeconomic factors, and age-related cataract: the Singapore Malay Eye study. Arch Ophthalmol 2010; 128(8): 1029-1035. 